\title{
Dynamic Penetration Studies in Crushed Rock under Atmospheric and Vacuum Conditions
}

\author{
David J. Roddy, ${ }^{*}$ John B. Rittenhouse, $\dagger$ and Ronald F. Scott $\ddagger$ \\ California Institute of Technology, Pasadena, Calif.
}

\begin{abstract}
A device was constructed to study dynamic penetration in erushed rock both in air and a high-vacuum $\left(10^{-5} \mathrm{~mm} \mathrm{Hg}\right)$ condition. The apparatus is designed to drop cylindrical, metal rods, pointed on one end, into cohesionless crushed rock material. Dynamic penetration is studied as a function of several particle sizes and mixtures of these particle sizes. Other factors considered are the density of packing, probe dimensions, vacuum pressure, and vacuum degassing rates. Experimental results show that the density of packing of the crushed rock particles is the dominant factor affecting the dynamic penetration. The maximum penetration occurs in air in the crushed rock with low-density packing. The minimum penetration occurs in air in densely packed material. Dynamic penetration in vacuum for the lowdensity and high-density packing lies between the results of penetration in air for the same packing conditions. At vacuum pressures above approximately $0.1 \mathrm{~mm} \mathrm{Hg}$, all penetration values approach the air penetration measurements.
\end{abstract}

\section{Introduction}

$\mathbf{I}$ view of the advent of lunar surface exploration, the installation of experiments designed to measure the mechanical properties of the lunar surface in unmanned space vehicles has become necessary. The results of such experiments, combined with chemical and geological analyses of the surface, will dictate the design of lunar landing craft and moving vehicles. Before equipment and apparatus can be designed to give information on the mechanical properties of a surface, however, a model of the surface must be considered.

Currently, investigators postulate a surface consisting of a layer of granular fragments of basic and ultrabasic rock overlying solid rock. Opinions differ regarding the thickness and chemical composition of this layer and the size and range of sizes of rock particles present in the layer. ${ }^{1-4,7-9}$ It also has been suggested that the particles may be sintered together or that the surface may consist of a rock froth. The possibility of the presence of a granular deposit, however, suggests the desirability of performing both static and dynamic penetration experiments by equipment mounted on a lunar landing spacecraft.

To determine the behavior of the material in such tests, several investigators in the fields of lunar research and spacecraft design have carried out static and dynamic studies in various granular soils under earth gravity in both vacuum

Presented at the ARS 17th Annual Meeting and Space Flight Exposition, Los Angeles, Calif., November 13-18, 1962. The study described in this report was conducted in the Materials Research Section, Jet Propulsion Laboratory. Support for J. B. Rittenhouse and R. F. Scott was under NASA Contract No. NASw-6, and support for D. J. Roddy was under Contract No. NsG-56-60, sponsored by NASA. The writers wish to express their appreciation for advice and assistance given by Bruce C. Murray, Research Fellow in Space Science, Division of Geological Sciences, California Institute of Technology, and Harrison Brown, Professor of Geochemistry, Division of Geological Sciences, California Institute of Technology. Leon T. Silver, Associate Professor of Geological Sciences, California Institute of Technology, kindly provided the olivine basalt. The writers are indebted to Leonard D. Jaffe, Chief, Materials Research Section, and Howard E. Martens, Assistant Chief, Materials Research Section, Jet Propulsion Laboratory, for their continued assistance in this project. The writers are indebted to Ellis P. Frank of the Jet Propulsion Laboratory and to Sandy Liu of the California Institute of Technology for their technical assistance in this study.

* Graduate Research Assistant, Division of Geological Sciences.

† Research Scientist, Lockheed Missiles and Space Company, Palo Alto, Calif.

₹ Associate Professor of Civil Engineering. and air conditions. One study indicated greater penetration in a vacuum for certain grain sizes, whereas for other grain sizes the penetration was greatest in the air. Another study found the maximum penetration to occur consistently in vacuum conditions. The differences in facts between these studies indicated that low-velocity penetration experiments under controlled high-vacuum conditions in cohesionless, crushed rock material were necessary. The objective of this work simply was to provide a framework for future investigations of the more detailed problems suggested by the initial study described here. The penetration behavior was correlated with the principles of soil mechanies and shown to be consistent with them.

\section{Experimental Techniques}

Speculation concerning the composition of the lunar surface has ranged widely between the major rock systems. Consequently, the choice of a "representative" or "average" type of rock for this study at first presented a problem. Preliminary penetration results on a tonalite, quartz diorite, and olivine basalt supported the conclusion that penetration is a function of the physical characteristies but not of the mineralogieal characteristics of the crushed rock. This is, of course, excluding any change in physical characteristics resulting from an unusual mineralogical composition as might be found in talc, mica, and other soft or plate-like minerals. This conclusion generally is substantiated by studies in the field of soil mechanics.

The choice of an olivine basalt from Pisgah Crater, San Bernardino County, Calif. for this penetration study was based on its availability as a fresh, unweathered rock of common terrestrial oceurrence which could be collected in bulk quantity. It also is reasonable to suspect that basalt may comprise one of the differentiated rock series making up a portion of the moon's crust. The rock was crushed and sieved to obtain "soils" in several particle sizes and ranges of size.

After the crushing and sieving was completed, a mieroscopic study was made of the various size fractions used in the penetration tests. Examination of the granular material shows an approximately equal distribution of the mineral composition throughout the various crushed size fractions. Table 1 and Fig. 1 show the particle size distribution of the various test samples, and a detailed description of the test rock is given in Ref. 5 .

The apparatus shown in Fig. 2 was designed to permit remote control of the dynamic penetration equipment in high vacuum. The equipment permitted eylindrical brass probes 
Table 1 Particle-size distribution of Pisgah Crater basalt from erushing series 1

\begin{tabular}{|c|c|c|c|c|c|c|}
\hline Mesh size screen nos. & Particle size, $\mu$ & \multicolumn{5}{|c|}{ Nominal mesh size } \\
\hline+28 & $>590$ & 0.05 & 0.02 & 0.00 & 0.00 & 0.00 \\
\hline$-28+35$ & $<590>420$ & 0.27 & 0.59 & 0.00 & 0.02 & 0.02 \\
\hline$-35+48$ & $<420>297$ & 8.05 & 67.65 & 0.15 & 0.05 & 0.03 \\
\hline$-150+200$ & $<105\rangle \quad 74$ & 9.68 & 0.10 & 0.54 & 10.91 & 7.98 \\
\hline$-200+270$ & $<74>53$ & 11.21 & 0.09 & 0.20 & 5.53 & 19.47 \\
\hline \multirow[t]{4}{*}{$-270+325$} & $<53>44$ & 4.94 & 0.04 & 0.06 & 1.64 & 14.03 \\
\hline & $<44>35$ & 3.98 & 0.05 & 0.20 & 1.20 & 4.13 \\
\hline & $<35>25$ & 9.11 & 0.04 & 0.15 & 2.62 & 10.70 \\
\hline & $<25>12$ & 10.88 & 0.26 & 0.76 & 4.31 & 17.25 \\
\hline \multirow[t]{2}{*}{ Loss in screening } & & 0.13 & 0.72 & 0.70 & 0.49 & 0.51 \\
\hline & & $\overline{100.00}$ & 100.00 & $\overline{100.00}$ & 100.00 & 100.00 \\
\hline
\end{tabular}

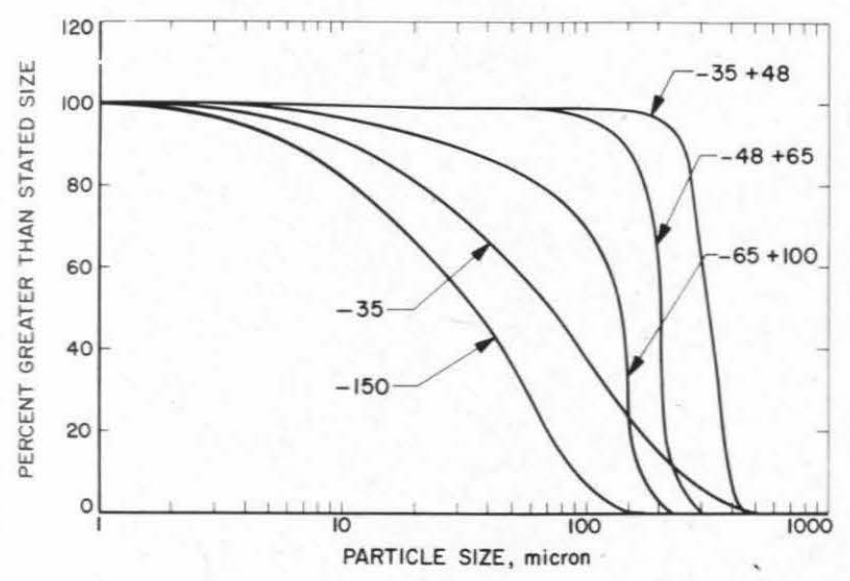

Fig. 1 Particle-size distribution of Pisgah Crater basalt

to drop down glass guide tubes into crushed rock in a container.

The apparatus consists of four equally spaced support legs of adjustable height upon which were mounted two eircular plates of adjustable spacing. The two circular plates were fitted with four equally spaced glass guide tubes for the penetrating probes. Two of the guide tubes could contain 1-cmdiam polished brass probes, whereas the two smaller tubes accommodated 0.6-em-diam probes. At the top of each tube an electromagnetic solenoid was mounted. The arbor of each solenoid engaged a pin through the top of each probe. Actuation of a solenoid pulled the pin and permitted a probe to fall freely to penetrate the crushed rock below.

The brass probes were $5 \mathrm{~cm}$ long. Two probes were $1 \mathrm{~cm}$ in diameter, weighed $27.5 \mathrm{~g}$, and had a $30^{\circ}$ half-angle on one end; two other probes were $0.6 \mathrm{~cm}$ in diameter, weighed $11.5 \mathrm{~g}$, and had a $30^{\circ}$ half-angle on one end.

The vacuum equipment used in this investigation included a glass bell jar on a stainless steel base-plate. The pumping system consisted of a 4 -in.-diam oil diffusion pump with a pumping speed of 750 liters/sec at $1 \times 10^{-3} \mathrm{~mm} \mathrm{Hg}$ backed by a rotary mechanical pump. The mechanical vacuum pump could be by-passed around the diffusion pump to serve also as the rough vacuum pump. A water-cooled high vacuum valve was placed above the diffusion pump; between the high vacuum valve and the base plate there was a refrigerated (liquid nitrogen or freon) baffle or cold trap. Thermocouple vacuum gages measured pressures from at-

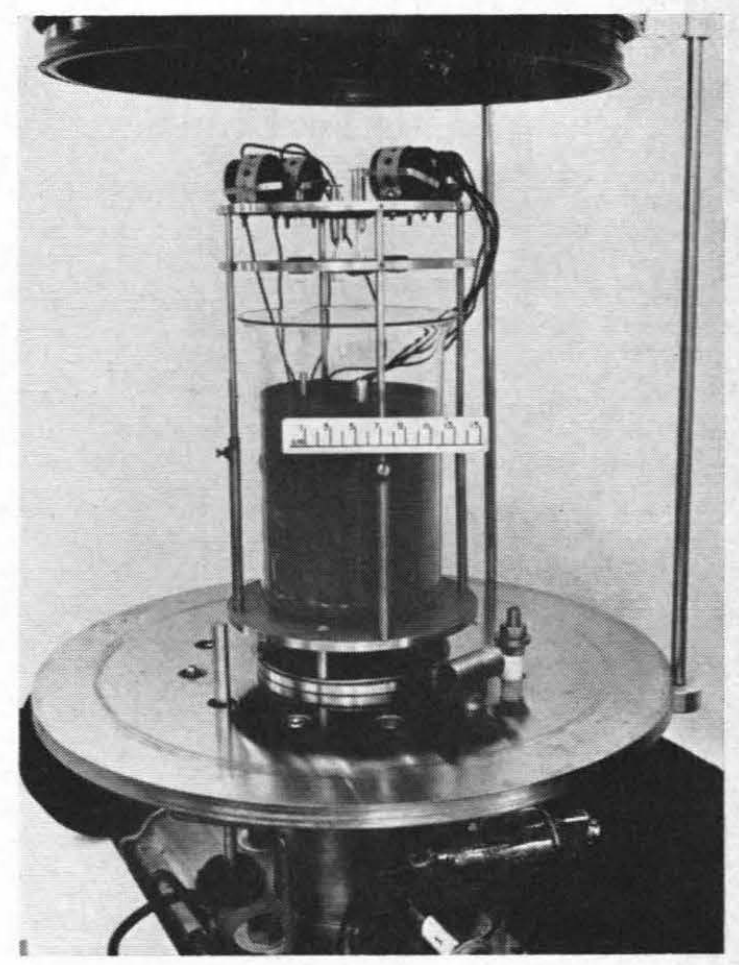

Fig. 2 Dynamic penetration equipment

mospheric to $10^{-3} \mathrm{~mm} \mathrm{Hg}$. Hot or cold eathode high vacuum gages were capable of measuring vacuum to $10^{-7} \mathrm{~mm} \mathrm{Hg}$. The system capability was usually in the low $10^{-5} \mathrm{~mm} \mathrm{Hg}$ or the high $10^{-6} \mathrm{~mm} \mathrm{Hg}$ vacuum region. Figure 3 shows the pressure-time behavior of the system during degassing of the soil.

In order to compare the various penetration values for different particle sizes, it was necessary to maintain approximately the same average density for each sample of a given packing condition. Consequently, proper filling of the container with the granular material to maintain a consistent value of packing and density of the crushed rock constituted a major problem in this study. However, in a statistical sense, this can be accomplished with the proper container filling procedure.

The lower density condition of the material was the most 
Table 2 Dynamic penetration in crushed rock (Pisgah Crater olivine basalt, crushing series 1)

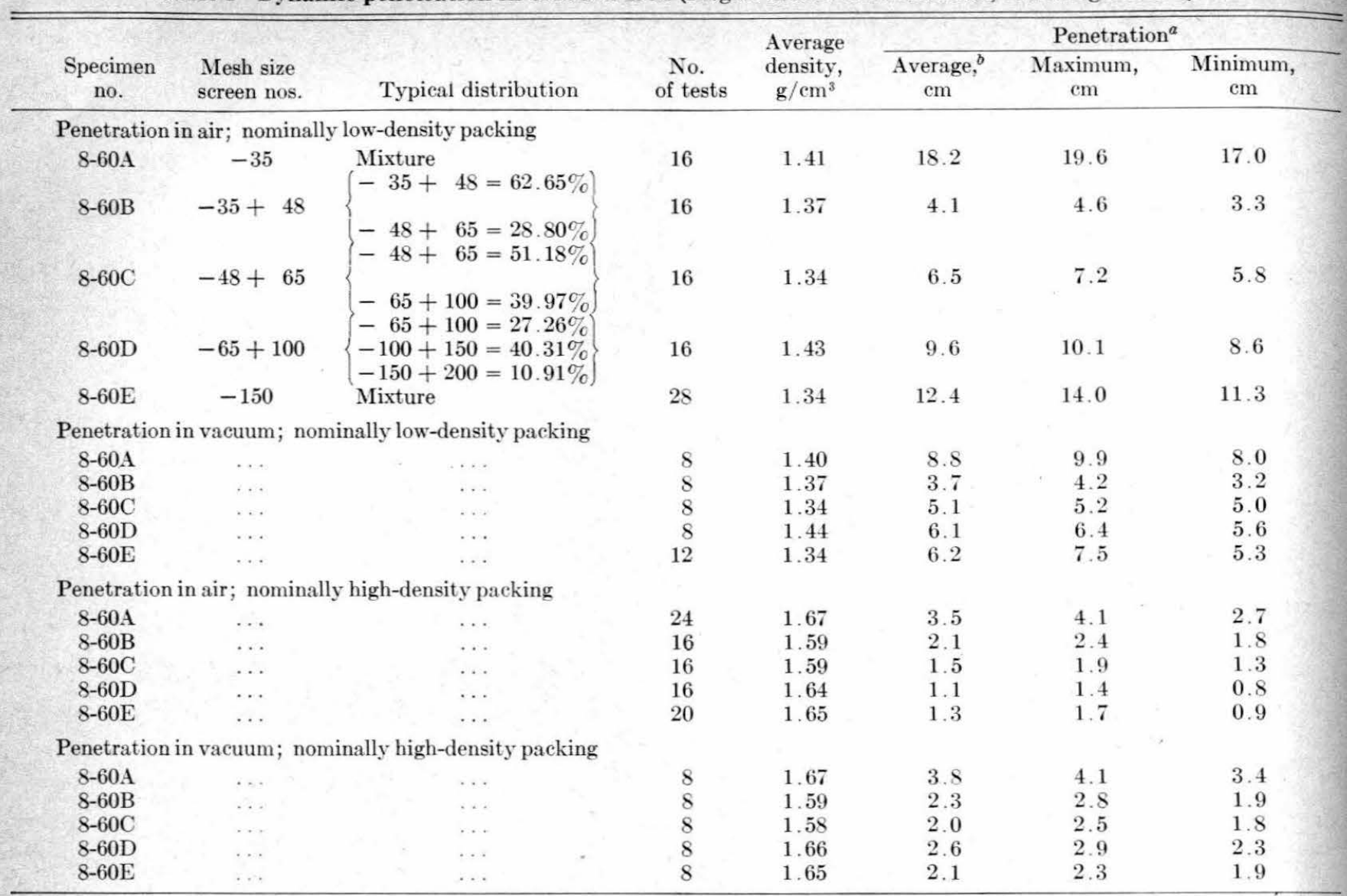

a Probes: brass, density $8.8 \mathrm{~g} / \mathrm{cm}^{3} ; 5 \mathrm{~cm}$ long and $1 \mathrm{~cm}$ diam, $27.5 \mathrm{~g} ; 5 \mathrm{~cm}$ long and $0.6 \mathrm{~cm}$ diam, $11.5 \mathrm{~g} ; 60^{\circ}$ angle at one end.

Arithmetic average.

difficult to achieve in a reproducible manner. This difficulty resulted primarily because any agitation or improper handling of the material in the container during or after the loading operation changed the low-density material to some more densely packed condition. In order to attain the lower density condition of the material, it was necessary to load the material in the container with a spoon, insuring that each spoon load was deposited carefully with a minimum of freefall. Obviously, this technique introduces considerable human error into the operation, but the penetration values reported are believed to be accurate with respect to the controlled conditions of these tests.

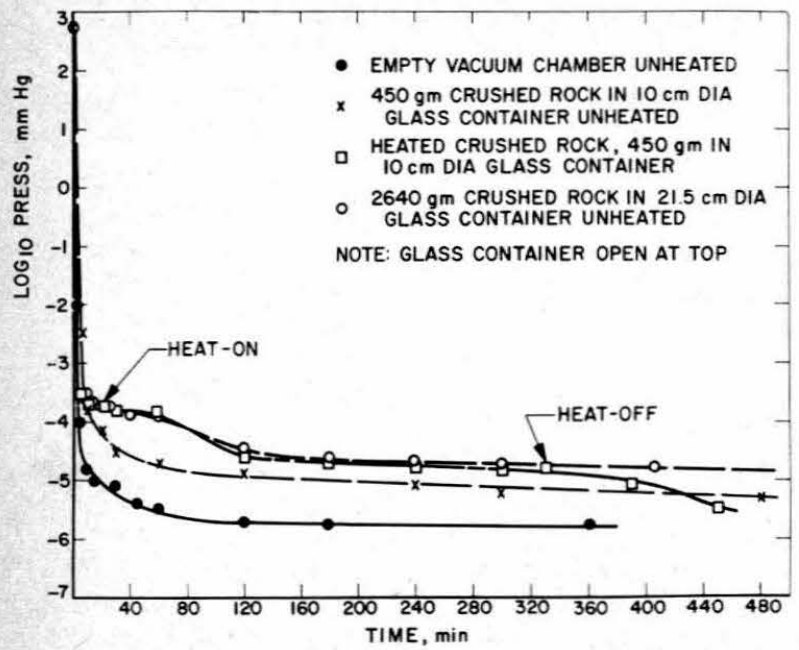

Fig. 3 Degassing in vacuum of erushed Pisgah Crater basalt
For the higher densities, a given weight of material was agitated by hand in the specimen container until the proper volume was obtained to produce the required density. Two ranges of densities of the crushed material were used. In one group material densities were from 1.59 to $1.67 \mathrm{~g} / \mathrm{cm}^{3}$, whereas in another group densities were from 1.34 to 1.44 $\mathrm{g} / \mathrm{cm}^{3}$. The measurement error of the exact depth of the material in the container results in an error in the calculation of the density of $\pm 0.05 \mathrm{~g} / \mathrm{cm}^{3}$.

Most of the experiments of dynamic penetration in vacuum were done with a vacuum in the low $10^{-5} \mathrm{~mm} \mathrm{Hg}$ region. The unheated crushed rock samples commonly were evacuated for at least $3 \mathrm{hr}$ but occasionally as long as $16 \mathrm{hr}$ prior to conducting a test. In vacuum penetration, the penetration depth was measured before and after the vacuum system was opened to the atmosphere.

For the dynamic penetration studies, the drop height was $16.0 \pm 0.5 \mathrm{~cm}$ in both air and vacuum. The $\pm 0.5-\mathrm{cm}$ limit in the drop height measurement is a function of the maximum roughness of the surface of the crushed rock material, since

Table 3 Effect of vacuum pressure on dynamic penetration (Pisgah Crater basalt, specimen no. 8-60E, - 150 mesh, density $1.35 \mathrm{~g} / \mathrm{cm}^{3}$ )

\begin{tabular}{ccrcc}
\hline \hline \multirow{2}{*}{$\begin{array}{c}\text { Vacuum } \\
\text { pressure, } \\
\text { mm Hg }\end{array}$} & $\begin{array}{c}\text { No. of } \\
\text { tests }\end{array}$ & $\begin{array}{c}\text { Average, } \\
\text { cm }\end{array}$ & $\begin{array}{c}\text { Maximum, } \\
\text { cm }\end{array}$ & $\begin{array}{c}\text { Minimum, } \\
\mathrm{cm}\end{array}$ \\
\hline 760 & 28 & 12.4 & 14.0 & 11.3 \\
1 & 12 & 12.9 & 13.6 & 12.3 \\
$10^{-1}$ & 12 & 6.1 & 6.7 & 5.5 \\
$10^{-2}$ & 12 & 6.0 & 6.5 & 5.6 \\
$10^{-5}$ & 12 & 6.2 & 7.5 & 5.3 \\
\hline \hline
\end{tabular}




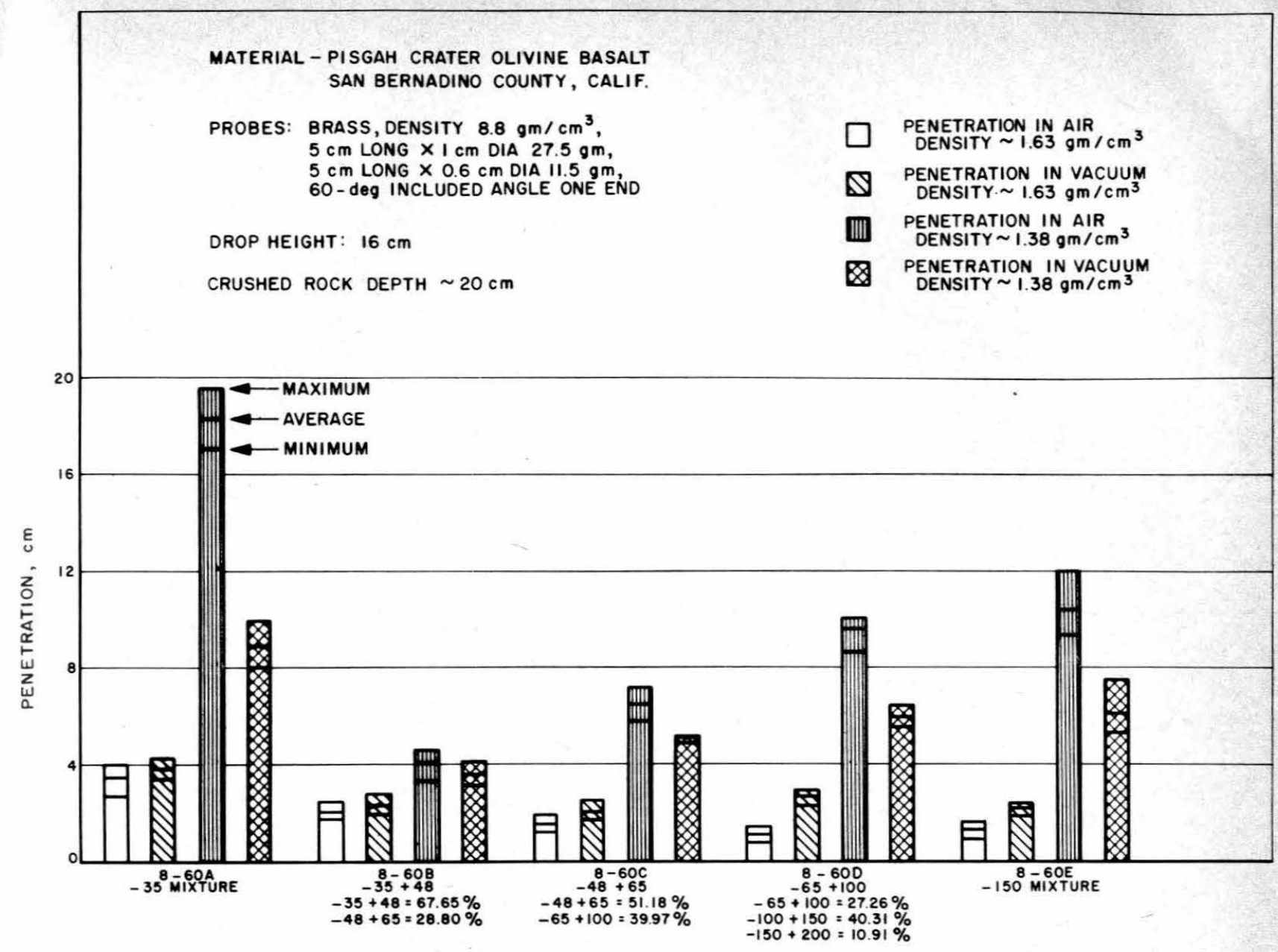

TYPICAL PARTICLE SIZE DISTRIBUTION

Fig. 4 Dynamic penetration in crushed rock

it was not possible to smooth the surface without disturbing the condition of the predetermined density of the specimen. An average velocity of $177 \mathrm{~cm} / \mathrm{sec}$ was calculated for the falling probes, and a constant depth of $20 \mathrm{~cm}$ of material in the container was maintained.

With the apparatus in place in the vacuum system, the electromagnets holding the probes were actuated individually to permit the probes to fall onto the crushed rock for each particle-size distribution and packing density. The depth of penetration of each probe was measured to the same limits as the drop distance, i.e., $\pm 0.1 \mathrm{~mm}$. The penetration data are reported as the depth of the point of the probe below the surface of the crushed rock.

Corollary experiments were performed to examine the effects of the probe distance from the soil container wall and base and the probe point angle. In addition, the variation of soil density and penetration depths with vibration and the penetration depths with the level and duration of vacuum were examined.

\section{Results}

The penetration results are presented in Table 2 and Fig. 4 . Experimental results indicate that the density of packing was by far the most dominant parameter affecting penetration. With particle sizes used in this study, the maximum average penetration, $18.2 \mathrm{~cm}$, occurred in air in the materials with low-density packing. The minimum penetration, 1.1 $\mathrm{cm}$, oceurred in air in the material with high-density packing. In air with the material of low-density packing the average penetration values ranged from 4.1 to $18.2 \mathrm{~cm}$, whereas in vacuum with the material of low-density packing the penetra- tion values ranged from 3.7 to $8.8 \mathrm{~cm}$. Penetration in vacuum in the material of high-density packing ranged from 2.0 to $3.8 \mathrm{~cm}$.

The effect of vacuum pressure on the penetration in the -150 mesh material with low-density packing is shown in Table 3. At a vacuum pressure of $1 \mathrm{~mm} \mathrm{Hg}$, the penetration is of the same order as for the same material in the same packing condition in air. When the vacuum pressure is reduced to $10^{-1} \mathrm{~mm} \mathrm{Hg}$ or to $10^{-2} \mathrm{~mm} \mathrm{Hg}$ (Table 3), the penetration values are the same as the penetration values found at the low $10^{-5} \mathrm{~mm} \mathrm{Hg}$ vacuum region. It should be noted that the vacuum pressure was not maintained for extended periods of time. For this reason, the effect of long-term degassing of grain surfaces should not be inferred from these data.

The effect of the two probe weights and two cone angles on the penetration results also was studied. These effects are shown in Table 4, where it can be seen that for the -150 mesh material in the low-density packing condition neither the probe weight nor the cone angle has an effect on the dynamic penetration in air. These values can be compared readily with similar results in Table 2 .

A motion picture film at 5000 frames/sec was taken of the dynamic penetration. Sequences showing experiments in vacuum, in air, and with the low- and high-density packing conditions of the crushed rock were included.

One feature brought out in the motion pictures of the dynamic penetration which readily could not be observed visually was the cratering and "splashing" action of the material as particle size decreased. There appeared to be larger craters formed in the higher density packing, and the eraters appeared to be larger with decreasing particle size. The 
Table 4 Effect of probe cone angle on dynamic penetration in air (Pisgah Crater basalt, specimen no. 8-60E, -150 mesh, density $1.38 \mathrm{~g} / \mathrm{cm}^{3}$ )

\begin{tabular}{ccc}
\hline $\begin{array}{c}\text { Cone } \\
\text { angle, deg }\end{array}$ & $\begin{array}{c}\text { Probe weight, } \\
\text { g }\end{array}$ & $\begin{array}{c}\text { Penetration, } \\
\mathrm{cm}\end{array}$ \\
\hline 90 & 27.5 & 12.2 \\
& 27.5 & 11.8 \\
& 11.4 & 12.5 \\
Average & 11.4 & 13.0 \\
60 & & 12.4 \\
& 27.5 & 12.8 \\
& 27.5 & 12.6 \\
Average & 11.4 & 12.2 \\
\hline \hline
\end{tabular}

"splashing" action, or ejection of the crushed rock upon impact and penetration of the probe, increased with decreasing particle size, was greater in air than in vacuum, and was greatest with the low-density packing condition in the erushed material with the nominal particle size of -150 mesh.

\section{Qualitative Theoretical Considerations}

A probe such as used in the present tests expends its energy upon penetrating the granular material in a variety of ways, but principally by inducing shearing stresses in the medium. Thus, apart from other considerations, the depth of penetration will depend in large part on the shearing strength of the granular material and on the dilatation phenomena that accompany shearing.

When a granular material shears, an expansion or contraction of the granular mass takes place, depending on the initial state of the packing of the material. ${ }^{6}$ In tests at atmospheric pressure wherein the particles are very closely spaced (densely packed), shearing stresses cause the grains in the failure zone to rise over the underlying particles, increasing the total volume by increasing the volume of void space. The increase in void volume means that external pore fluid (gas or liquid) must be drawn in and energy must be supplied to draw this fluid into the granular material. In particular, the flow is caused by a drop in the fluid pressure in the shearing zone arising from the expansion of the granular mass, and this drop in fluid pressure has the additional effect of raising the intergranular stresses (or forces at the points of contact of particles) in the shearing region. Since the resistance of a granular material to shear is directly proportional to the intergranular stresses imposed upon it, the energy required to shear a dense granular material is increased both as a result of the rise in intergranular stresses and as a result of the necessity of drawing in pore fluid.

In tests at atmospheric pressure on a loose material, the volume change upon shear is negative since the void volume of the material contracts. In this case the pressure in the pore fluid is raised, initiating a flow of the fluid away from the shearing zone and reducing the intergranular pressures in the region of shear stresses. In extreme cases the increase of fluid pressure will be such as to reduce the forces at intergranular contacts to zero, and the mass becomes essentially fluid, having an extremely low resistance to shear.

The state of packing or density of the material is seen to be the most important single parameter influencing penetration in granular materials. Thus, when air fills the voids of the granular material, the energy expended by the projectile in a dense packing goes toward moving the grains relative to one another (shearing) under momentarily increased intergranular stresses and toward drawing air into the zone of shear. The apportionment of energy depends upon the size of the pores in the granular material, since the ease with which air flow takes place depends on a power of the pore diameter; however, in general, the resistance to penetration is high. In a vacuum, the increase in strength caused by the phenomena associated with a pore fluid does not take place, and the depth of penetration would be expected to be higher, for the same value of density of packing. The ratio between the air and vacuum penetrations will depend upon, among other things, the particle size of the material.

Loosely packed granular material in air would exhibit, to a degree depending on its looseness, the tendency to fluidization or liquefaction previously described. The reduction in or even lack of intergranular contact would result in a very low resistance to penetration. This effect again would vary with the pore size, or indirectly with the particle size, and affect the ability of the pore fluid to escape. In a vacuum, the behavior arising from the presence of the fluid would be absent, and intergranular contact in the mass of the material would be, to a considerable extent (at present penetration velocities), maintained. In this case of loose packing, penetration therefore would be decreased in a vacuum.

Since air is present in the voids of the granular material initially at atmospheric pressure, any reduction of air pressure at the surface of granular material results in a flow of air from the voids to the surface. This flowing air exerts a drag force on the intervening particles; therefore, the greater the pressure difference, the more rapid the flow and the greater the drag on the particles. The effect on a particle depends on its surface-to-volume ratio, and thus finergrained material (with a high surface-to-volume ratio) will be moved upward by the air flow under smaller pressure gradients than coarse materials. If the structure of the granular material is not to be disturbed, it therefore is essential to reduce the pressure at the surface gradually, so that the air flow is small and the disturbance minimized. The effects of rapid pressure reduction are most noticeable in fine particle sizes, in which the greater relative drag forces on the smaller particles result in some sorting of the materials and an extreme change in the state of packing of the soil.

Proper throttling of the valve connecting the vacuum chamber to the rotary mechanical vacuum pump until the pressure in the chamber was below $10^{-2} \mathrm{~mm} \mathrm{Hg}(10 \mu)$ decreased the initial outgassing rate and rate of pressure drop so that a minimum disturbance of the packing condition of the material was achieved. This precaution was exercised for all of the dynamie penetration experiments in vacuum.

It is extremely difficult to prepare samples of coarsegrained soils in a uniformly loose condition and almost equally difficult to obtain very dense test specimens of very finegrained particles, so that, if the state of density is not observed, tests on coarse soils are apt to be carried out on relatively dense material, whereas those on fine-grained material are performed on the soil in a loose state. Thus, in such tests, the differences in penetration behavior in a vacuum are not due directly to the grain size. Additionally, however, the shear strength properties of a granular material depend on the characteristics of the mineral surfaces at points of contact.

In a given volume of coarse soil, there are many fewer such contacts than in the same volume of fine-grained soil, and, as a consequence, the outgassing of the contact surfaces of a coarse-grained soil at high vacua is much more effective than that of a fine soil. Consequently, when two soils, one coarse and the other fine, in the same state of packing or density are subjected to the same high vacuum for the same time, the depth of a projectile's penetration will not be the same in the two materials. Because outgassing of a surface removes contaminants, the coefficient of friction between two mineral surfaces tends to increase in high vacua, and thus, other things being equal, as in the foregoing, the depth of penetration in a coarse soil in a high vacuum will be less than in a fine soil, not as a direct result of the grain size, but as an indirect one. In addition, if two soils, one containing a wide 
range of grain sizes and the other containing particles of a uniform size, are both tested (in air and vacuum) at the same unit weight (used as the criterion of denseness in these experiments), the well-graded material will be in a relatively looser state than the uniform soil, and greater depths of penetration will be recorded in it. Thus it is seen that the distribution of grain sizes also affects the results.

Further experiments are required to elucidate the effect of vacuum level and duration on the effective coefficient of friction of soils of different grain sizes.

\section{Conclusions}

In summary, it may be said that, on a qualitative theoretical basis, other factors being equal, dynamic penetration of freely falling probes into a densely packed cohesionless granular mass in air will be very much less than into a loosely packed granular material in air. Penetration into a loosely packed granular material in vacuum will be less than into a loosely packed granular material in air, and penetration into a densely packed mass in vacuum will be greater than into a densely packed mass in air. The results of the experiments tend to confirm these conclusions and other tentative quali- tative deductions on the frictional behavior of soils exposed to vacuum conditions.

\section{References}

${ }^{1}$ Fielder, G., Structure of the Moon's Surface (Pergamon Press, New York, 1961), Chap. 9.

${ }^{2}$ Gold, T., "Dust on the moon," Vistas in Astronautics (Pergamon Press, New York, 1959), Vol. 2, pp. 261-266.

${ }^{3}$ Jaeger, J. D. and Harper, A. F. A., "Nature of the surface of the moon," Nature 166, 1026 (1950).

${ }^{4}$ Kuiper, G. P., "The exploration of the moon," Vistas in Astronautics (Pergamon Press, New York, 1959), Vol. 2, p. 273.

${ }^{5}$ Roddy, D. J., Rittenhouse, J. B., and Scott, R. F., "Dynamic penetration studies in crushed rock under atmospheric and vacuum conditions," TR 32-242, Jet Propulsion Lab. (April 6, 1962).

${ }^{6}$ Scott, R. F., Principles of Soil Mechanics (Addison-Wesley, Reading, Mass., 1963), pp. $325 \mathrm{ff}$.

' Urey, H. L., "Composition of the moon's surface,"' Z. Physik. Chem. Neve Folge. Bd. 16, S346-357 (1958).

${ }^{8}$ Whipple, F. L., "On the lunar dust layer," Vistas in Astronautics (Pergamon Press, New York, 1959), Vol. 2, pp. 267-272.

${ }^{9}$ Whipple, F. L. and Fireman, E. L., "Calculation of erosion in space from cosmic-ray exposure ages of meteorites," Nature 183, 1315 (1959).

\title{
Analysis of Foldability in Expandable Structures
}

\author{
H. U. Schuerch* and G. M. Schindler ${ }^{\dagger}$ \\ Astro Research Corporation, Santa Barbara, Calif.
}

\begin{abstract}
Outlines for a general theory of large deformations, including folding of arbitrary inextensible membranes, are presented. The approach to the problem uses isometric mapping techniques complemented by the additional topological constraints of the folding problem in real membrane structures. The theory is applied to an inextensible membrane in the form of a torus. Rigorous solutions are found for a particular class of deformations. Theoretical results are verified qualitatively by realization of predicted folding patterns on two torus models.
\end{abstract}

\section{Nomenclature}

E,F

$\mathrm{S}$

$\mathbf{X}=$ radius vector

$f, g, h, k=$ auxiliary functions of $(u, v)$

$n \quad=$ integer

$p \quad=$ deformation parameter

$u, v=$ curvilinear surface coordinates

$x, y, z=$ Cartesian coordinates

$\lambda=$ direction of propagation on surface

$\rho \quad=$ radius of meridional circular torus section

Superscripts and subscripts

* $\quad=$ function of the deformed surface

$(u)$, etc. $=$ variable of a function

$u$, etc. $=$ partial derivative of a function with respect to the variable $u$

Presented at the IAS Annual Summer Meeting, June 19-22, 1962; revision received July 27, 1962. The material presented in this paper has been prepared under Contract NASr-8, sponsored by NASA Office of Research Grants and Contracts.

* President.

$\dagger$ Senior Scientist and Consulting Specialist for Differential Geometry.

\section{Introduction}

FXPandable pneumatic structures, i.e., structures that can be packaged into small volumes and erected by inflation into relatively rigid devices, have been considered for a number of space missions. Of particular interest is the design of expandable large-sized manned orbital space laboratories in the form of a modified torus, ${ }^{1}$ either partially or fully constructed from flexible materials.

Other examples where expandable structures can find applications are the large surface required for reflectors of electromagnetic radiation (Echo satellite), collectors for 'solar energy, and expanding and retracting devices for manipulation of instruments during flight, re-entry, or for operations after landing on foreign celestial bodies.

In many of these applications, the operating pressure and/ or the size of the expandable structure is such that considerable structural forces arise from pressurization. This requires a wall construction that is strong and, as a consequence, stiff, at least in directions tangential to the surface. Thus, although optimum design and materials selection may result in a thin-walled strong shell that retains sufficient bending compliance to allow relatively sharp bending radii, these designs exhibit normally sufficient membrane stiffness to limit the membrane strains to small values. As a limiting 